\title{
Front-of-package nutrition references are positively associated with food processing
}

\author{
Anthea Christoforou' ${ }^{1}$ Naomi Dachner ${ }^{1}$, Rena Mendelson ${ }^{2}$ and Valerie Tarasuk ${ }^{1, *}$ \\ 'Department of Nutrition Sciences, University of Toronto, Toronto, Ontario, Canada, M5S 3E2: ${ }^{2}$ School of Nutrition, \\ Faculty of Community Services, Ryerson University, Toronto, Ontario, Canada
}

Submitted 30 October 2016: Final revision received 10 March 2017: Accepted 21 April 2017: First published online 15 June 2017

\begin{abstract}
Objective: Foods characterized by a high degree of processing are pervasive in the global food supply and concerns have been raised about their contribution to the escalating burden of diet-related disease. It has been suggested that the dominance of these products relates in part to their aggressive on-package marketing. The purpose of the present study was to assess the relationship between the extent and nature of front-of-package (FOP) nutrition references on products sold in Canadian supermarkets and the level of food processing.

Design: FOP references were recorded from all packaged foods. Nutrition references were classified as 'negative' and 'positive' and further differentiated in terms of the use of regulated and unregulated text. Foods were coded for level of processing, using three different classification systems. Logistic and negative binomial regression analyses were conducted to assess associations.

Setting: Three large Toronto supermarkets, from the top Canadian food retailers. Subjects: Packaged foods ( $n$ 20 520).

Results: Forty-one per cent of products had FOP nutrition references. Irrespective of the classification system considered, the most processed category comprised the greatest proportion of products and nearly half of these bore FOP references. Foods deemed most processed were more likely than less processed products to bear FOP references and regulated and unregulated references to negative ingredients, but they were equally or less likely to bear positive nutrition references, depending on the classification system.

Conclusions: The greater frequency of FOP nutrition references on heavily processed foods raises questions about the extent to which discretionary FOP labelling supports public health efforts to promote healthy eating.
\end{abstract}

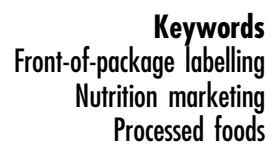

Ultra-processed foods have come to dominate the global food supply ${ }^{(1)}$. In Canada, the contribution of ultraprocessed products to household food purchases was $54.9 \%$ in $2001^{(2)}$ and examination of the most recent Canadian Community Health Survey revealed these foods made up $48 \%$ of energy consumed by Canadians ${ }^{(3)}$. Similar trends have been observed in other high-income countries and minimally processed, staple foods are increasingly being displaced by ultra-processed products in low- and middle-income settings as well ${ }^{(4-6)}$. While a study of household purchasing patterns in the USA between 2002 and 2012 suggested that trends in the purchase of highly processed foods and beverages have stabilized in that country, and this may be true in Canada as well, highly processed products comprised $61 \%$ of energy purchased by US households in $2012^{(7)}$. The high consumption of extensively processed foods is a matter of public health concern because of the nutrition profile of these products.
Despite differences in the criteria applied by different research groups to identify processed foods, studies have consistently documented higher concentrations of sugar, sodium and saturated fats among products deemed most processed $^{(4,7-10)}$. Diets high in ultra-processed products have been found to increase risk of weight gain ${ }^{(11)}$ and the metabolic syndrome ${ }^{(12)}$, and some authors have argued that the increased reliance on these foods has contributed to a parallel rise in the burden of chronic, diet-related disease $^{(2,5)}$.

It has been proposed that the dominance of ultraprocessed foods and beverages in the diet relates to their aggressive and strategic on-package marketing ${ }^{(1,13,14)}$, but there has been no systematic examination of the relationship between the level of food processing and nutrition labelling practices. In Canada, as in the USA and many other countries, the only mandatory nutrition information appearing on packaged foods and beverages 
is a nutrition facts table, typically displayed on the back of the package. The use of front-of-package (FOP) nutrient content and disease-risk reduction claims is regulated via compositional criteria and prescribed wording in Canada $^{(15)}$. Specifically, nutrient content claims exist for nutrients with established recommended daily intakes or reference standards, and their use is permitted on products containing prescribed amounts of these nutrients per serving ${ }^{(15)}$. Disease-risk reduction claims, similarly, are permitted on foods that contain set levels of energy and/or nutrients per serving based on scientific evidence that has established a relationship between certain elements of healthy diets and the reduction of the risk of developing chronic diseases ${ }^{(15)}$. These claims are intended to provide readily accessible information to help guide consumers towards healthier food choices, while also creating incentives for manufacturers to reformulate products to improve their healthfulness ${ }^{(16)}$. The decision of whether or not to display regulated claims rests with the manufacturer, however, and manufacturers are free to display other unregulated text, symbols and rating systems. A myriad of such claims, symbols and systems has been introduced by food manufacturers (e.g. Kellogg's 'Get the Facts') and third parties (e.g. the Whole Grain Council); their use requires no compliance with the compositional criteria governing regulated claims.

A recent survey of packaged foods in Canada found discretionary nutrition labelling, including nutrient content and disease-risk reduction claims and summary systems, on nearly half of products ${ }^{(17)}$. Manufacturer- and thirdparty-endorsed summary indicator systems and symbols were found on one-fifth of products and appeared in 158 unique formats ${ }^{(17)}$. While most research has not differentiated regulated and unregulated FOP references, studies of specific food categories have found $30-60 \%$ of products bearing unregulated text ${ }^{(18,19)}$. The high density of FOP nutrition references observed on breakfast cereals, mixed dishes, novel beverages and meal replacements ${ }^{(17,20,21)}$ suggests that discretionary on-package references to nutrition may be more common on products characterized by a high level of processing. It is well documented that FOP nutrition references are not necessarily indicative of nutritionally superior products ${ }^{(22-24)}$, but there is also considerable evidence that the presence of such references influence consumer purchasing ${ }^{(25,26)}$, raising questions about the extent to which processed food manufacturers' use of FOP nutrition references functions to reinforce the presence of these foods in the diet.

Drawing on data from a survey of packaged foods sold in Canadian supermarkets, the purpose of the present study was to assess the relationship between the extent and nature of FOP nutrition references on products and the level of food processing. Our analysis of FOP text and graphics differentiated manufacturers' use of regulated and unregulated text, while at the same time assessing the frequency of FOP references to nutrients and ingredients that are widely regarded as important to minimize, and those seen as important to maximize, in food selections for optimal health ${ }^{(27-31)}$. In the absence of a single, standardized classification system to grade foods in the North American food supply by level of processing, we employed three distinct frameworks to define food processing $(7,32,33)$ to allow for consideration of salient differences in the conceptualization of processing in this context.

\section{Methods}

\section{Data collection}

A comprehensive survey of all labelling found on the front of all packaged foods and beverages sold in major Toronto grocery stores was conducted between July 2010 and August $2011^{(18,34)}$. A single store was selected, by convenience sampling, from each of the top three food retailers in Canada (Loblaw's, Metro and Sobeys), representing $71 \%$ of the total Canadian retail market share ${ }^{(35)}$. Data collectors systematically recorded all descriptive text on the front of packaged foods, including product identifiers (i.e. brand and product name, variety and product size), nutrient content claims, quantitative statements, generic and product-specific health claims, thirdparty- (e.g. The Heart and Stroke Foundation of Canada's 'Health Check') and manufacturer- (e.g. Kraft's 'Sensible Solutions') developed symbols and summary systems which display or score nutrient content using thresholds or proprietary algorithms ${ }^{(36)}$, as well as any other descriptive or implied references emphasizing the presence or absence of a specific nutrient or constituent. Fresh produce, meat, poultry, fish, and dried herbs and spices were excluded from the sample because they were unlikely to bear nutrition labelling. Products found in the pharmacy and infant food sections were also excluded because these products are designed for specific population subgroups and special dietary usage.

After removing duplicate products (i.e. identical products found in more than one store), 20520 unique packaged items were captured in the database. Products were considered unique if they differed from similar products on the basis of any product identifier.

\section{Data analysis}

Each product was coded for the presence of any reference to nutrition (e.g. summary systems and symbols, quantifying statements, nutrient content and health claims). Nutrition references were further classified as 'negative' if they conveyed the reduction or absence of a nutrient or food constituent to discourage (e.g. 'low sodium', 'trans fat free', 'no added sugar') and 'positive' if they highlighted the presence or addition of a nutrient to encourage (e.g. 'good source of calcium', 'high in fibre'). Positive and negative nutrition references were further differentiated in terms of the use of regulated and unregulated text. 
Regulated nutrition references (i.e. nutrient content and disease-risk reduction claims) were identified by the prescribed wording and permitted wording variations outlined in the Canadian Food and Drug Regulations ${ }^{(37)}$ and the Canadian Food Inspection Agency's Guide to Food Labelling and Advertising ${ }^{(38)}$. Regulated references which indicated reformulation through the reduction of a particular negative constituent (e.g. 'reduced sodium') were also identified. Unregulated nutrition references included all quantifying statements, summary systems and symbols issued by the manufacturer or a third party as well any other text inconsistent with current prescribed wording for regulated claims. Finally, the total number of nutrition references appearing on a product was coded for each product. Verification of the data entry and coding was conducted on a sub-sample of products and discrepancies resolved by two members of the research team who were not involved in the data collection.

All products were classified by level of food processing, applying three distinct classification systems which have all been applied to the North American food supply ${ }^{(2,3,7-10,39,40)}$ but differ slightly in their determination of high levels of processing. The International Food Information Council's (IFIC) classification system ${ }^{(33)}$ was developed by IFIC in the Understanding our Foods Communication Toolkit and designed for use in highincome countries; its intended purpose was to define processed foods for consumers and clear 'misinformation about modern food production,(33). It grades products based on the relative complexity of processing and the physical, chemical and sensory changes in foods resulting from processing, while also differentiating convenience products. IFIC's classification of processed foods has been applied to consumption data from the $\mathrm{USA}^{(10,40)}$. The NOVA system, developed by Monteiro and colleagues at the University of São Paulo, defines food processing as the physical, biological or chemical processes after their separation from nature and prior to 'culinary preparation' and differentiates foods by nature, extent and purpose of food processing ${ }^{(3,32)}$. NOVA was developed to assess the role of food processing on the nature of diets and related states of health and well-being ${ }^{(32)}$, and has been applied to food purchasing and consumption data from a number of countries including Brazil, the UK and Canada ${ }^{(41)}$. The classification system developed by Poti and colleagues, while guided by the NOVA system and also focused on the degree of industrial processing, reflects the complexity of food processing inherent to the US food supply ${ }^{(7)}$. It has also been used in studies of food purchasing and consumption from the USA ${ }^{(7,39)}$. A summary of key differences and similarities in the determination of the highest level of food processing in each classification system is presented in Table 1. A fuller description of the classification criteria specific to each level of processing in these three systems is presented in the online supplementary material, Supplemental Table 1.

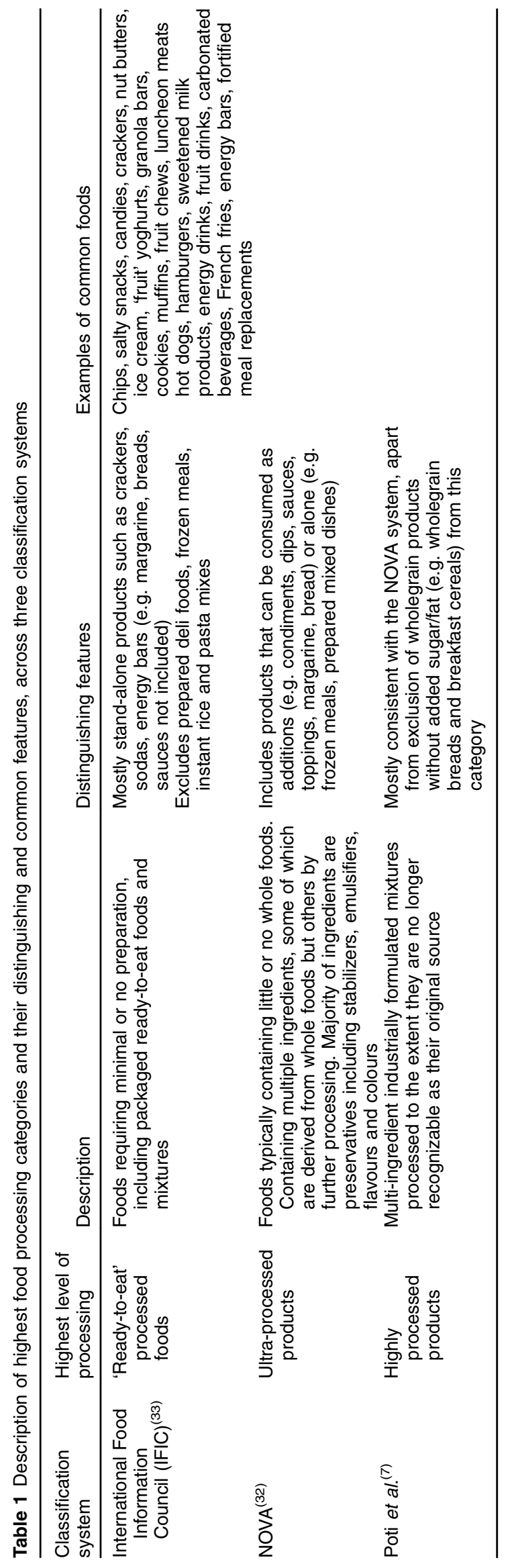


Binary logistic regression models were used to assess the relationship between the presence and nature (i.e. 'negative' or 'positive') of nutrition references and the level of product processing. Similar models were used to examine the relationship between references classified as unregulated and regulated and level of processing. The association between the extent (i.e. total number) of nutrition references on a product and level of processing was assessed using negative binomial regression models, appropriate for count outcome variables of this nature (e.g. values of $0,1,2,3, \ldots)^{(42)}$.

All analyses were conducted using the statistical software package SAS version 9.4. A $P$ value less than 0.05 was deemed statistically significant.

\section{Results}

Presence and nature of front-of-package references Forty-one per cent ( $n$ 8324) of all products surveyed bore some form of FOP nutrition reference, but there were marked differences in the proportion of products bearing FOP nutrition references within individual food groups (Fig. 1). Of the products bearing FOP nutrition references, $38 \%$ referenced the absence or reduction of a negative nutrient, $29 \%$ the presence or addition of a nutrient to encourage, and $23 \%$ referenced both negative and positive nutrients. Ten per cent of FOP nutritionally referenced products did not make specific reference to a single nutrient but included general health and wellness claims, manufacturer and third-party issued FOP summary systems and symbols. Twenty-two per cent ( $n$ 4538) of products bore a regulated reference which was negative and $15 \%$ ( $n$ 2985) one which was positive. Negative unregulated references appeared on $10 \%$ ( $n$ 2110) of products and positive unregulated references on $8 \%$ ( $n$ 1689). Regulated references which indicated reformulation were observed on $2 \%(n 492)$ of all products. In total, $24 \%$ ( $n$ 4925) of products bore an unregulated FOP nutrition reference.

\section{Relationship between front-of-package references and level of processing}

Irrespective of the classification system considered, the most processed category comprised the greatest proportion of products in our database and nearly half of these foods bore FOP nutrition references (Fig. 2). The nature of FOP references found on products, by level of processing, is presented in Table 2. Almost one-third of foods in the most processed category of each classification system bore FOP references to the negative nutrients, but the proportion with references to positive nutrients ranged from 19.3 to $24.5 \%$ (Table 2 ).

The most processed products were significantly more likely to have a nutrition reference than products in lesserprocessed categories (Table 3), but they were also more likely to make FOP references to multiple nutrients. Results from the negative binomial model showed that across classification systems, foods deemed most processed bore, on average, significantly more nutrition references than did products in lesser-processed categories (Table 4).

Products in the most processed category of each classification system were significantly more likely than less processed products to bear a negative nutrition reference (Table 3). Both regulated and unregulated negative references were significantly more likely to appear on foods classified as most processed than on lesserprocessed foods (Table 3). A closer examination of the negative references on products deemed most processed

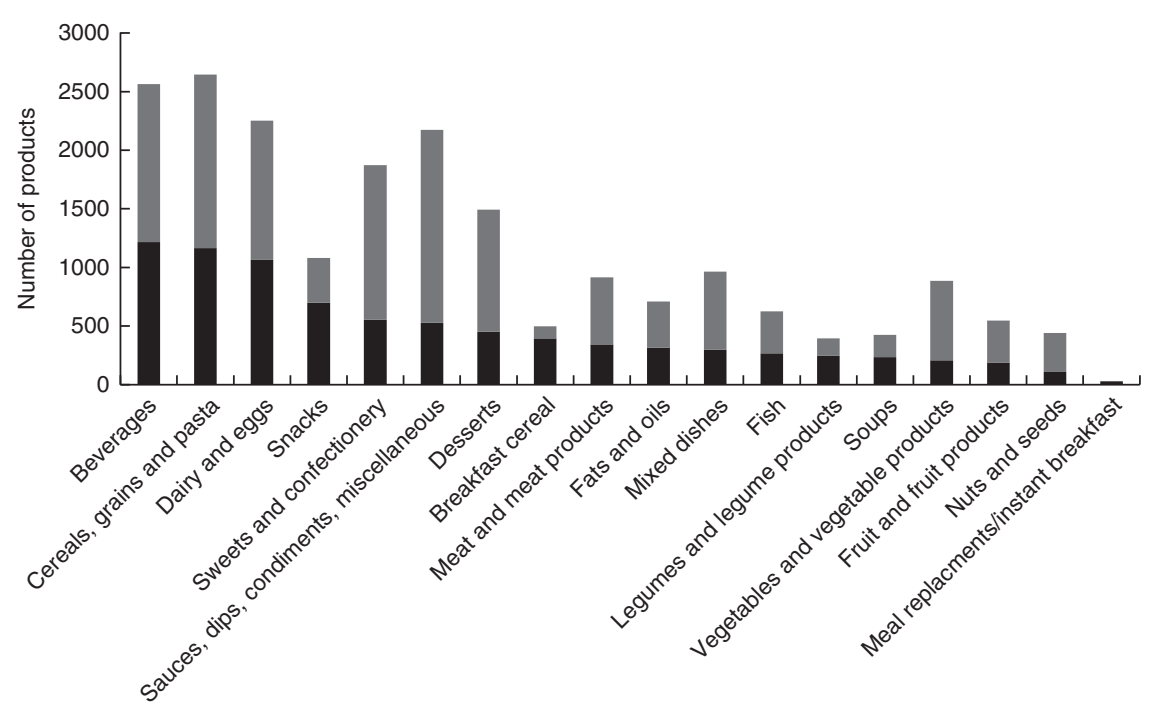

Fig. 1 Number of products with any front-of-package (FOP) nutrition reference ( $\square$, any FOP nutrition reference; $\square$, no FOP nutrition reference), by food category, among packaged foods ( $n$ 20520) from three large Toronto supermarkets, Canada, July 2010-August 2011 


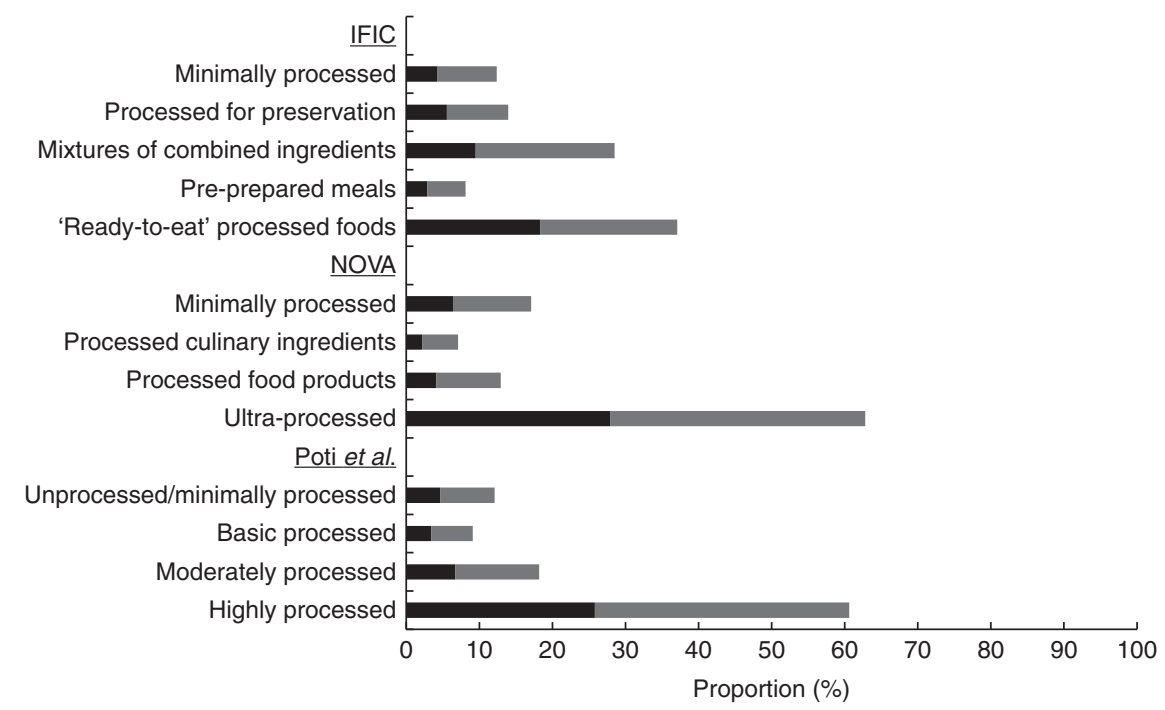

Fig. 2 Proportion of front-of-package (FOP) nutrition references ( $\square$, any FOP nutrition reference; $\square$, no FOP nutrition reference), by level of processing, across three classification systems, on packaged foods ( $n$ 20520) from three large Toronto supermarkets, Canada, July 2010-August 2011 (IFIC, International Food Information Council classification system(33); NOVA, system developed by Monteiro and colleagues ${ }^{(32)}$; Poti et al., classification system developed by Poti and colleagues ${ }^{(7)}$ )

Table 2 Frequency of front-of-package (FOP) nutrition references, by level of processing, across three classification systems, on packaged foods ( $n$ 20 520) from three large Toronto supermarkets, Canada, July 2010-August 2011

\begin{tabular}{|c|c|c|c|c|c|c|c|c|c|c|c|c|c|c|}
\hline \multirow{3}{*}{$\begin{array}{l}\text { Classification system/ } \\
\text { processing level }\end{array}$} & \multicolumn{14}{|c|}{ Type of FOP reference } \\
\hline & \multicolumn{2}{|c|}{$\begin{array}{c}\text { Any } \\
\text { negative }\end{array}$} & \multicolumn{2}{|c|}{$\begin{array}{l}\text { Any } \\
\text { positive }\end{array}$} & \multicolumn{2}{|c|}{$\begin{array}{l}\text { Any } \\
\text { regulated } \\
\text { negative }\end{array}$} & \multicolumn{2}{|c|}{$\begin{array}{c}\text { Any } \\
\text { unregulated } \\
\text { negative }\end{array}$} & \multicolumn{2}{|c|}{$\begin{array}{l}\text { Any } \\
\text { regulated } \\
\text { positive }\end{array}$} & \multicolumn{2}{|c|}{$\begin{array}{c}\text { Any } \\
\text { unregulated } \\
\text { positive }\end{array}$} & \multicolumn{2}{|c|}{$\begin{array}{l}\text { Any symbol } \\
\text { system }\end{array}$} \\
\hline & $n$ & $\%$ & $n$ & $\%$ & $n$ & $\%$ & $n$ & $\%$ & $n$ & $\%$ & $n$ & $\%$ & $n$ & $\%$ \\
\hline $\begin{array}{l}\text { Total } \\
\text { IFIC }\end{array}$ & 5148 & $25 \cdot 1$ & 4334 & $21 \cdot 1$ & 4538 & $22 \cdot 1$ & 2110 & $10 \cdot 3$ & 2985 & $14 \cdot 6$ & 1689 & $8 \cdot 2$ & 1529 & $7 \cdot 5$ \\
\hline Minimally processed & 266 & 10.4 & 609 & 23.9 & 191 & 7.5 & 167 & $6 \cdot 6$ & 358 & $14 \cdot 0$ & 237 & $9 \cdot 3$ & 80 & 3.1 \\
\hline Processed for preservation & 593 & $20 \cdot 7$ & 766 & $26 \cdot 8$ & 571 & $20 \cdot 0$ & 140 & 4.9 & 611 & 21.4 & 194 & $6 \cdot 8$ & 287 & $10 \cdot 0$ \\
\hline Mixtures of combined ingredients & 1434 & $24 \cdot 6$ & 840 & 14.4 & 1251 & 21.4 & 448 & $7 \cdot 7$ & 598 & $10 \cdot 3$ & 276 & 4.7 & 394 & 6.6 \\
\hline Pre-prepared meals & 421 & $25 \cdot 0$ & 251 & $15 \cdot 1$ & 308 & 18.5 & 216 & $13 \cdot 0$ & 216 & $13 \cdot 0$ & 886 & 11.6 & 138 & 8.3 \\
\hline $\begin{array}{l}\text { 'Ready-to-eat' processed } \\
\text { NOVA }^{(32)}\end{array}$ & 2434 & $32 \cdot 0$ & 1868 & $24 \cdot 5$ & 2217 & $29 \cdot 1$ & 1139 & $15 \cdot 0$ & 1202 & $15 \cdot 8$ & 886 & 11.6 & 630 & $8 \cdot 3$ \\
\hline Minimally processed & 548 & $15 \cdot 6$ & 901 & $25 \cdot 6$ & 486 & $13 \cdot 8$ & 188 & $5 \cdot 3$ & 705 & $20 \cdot 0$ & 215 & $6 \cdot 1$ & 224 & $6 \cdot 4$ \\
\hline Processed culinary ingredients & 191 & $13 \cdot 1$ & 342 & 23.5 & 183 & $12 \cdot 6$ & 37 & 2.5 & 270 & $18 \cdot 5$ & 139 & $9 \cdot 6$ & 86 & $5 \cdot 9$ \\
\hline Processed food products & 466 & $17 \cdot 5$ & 435 & $16 \cdot 3$ & 364 & 13.7 & 205 & $7 \cdot 7$ & 303 & 11.4 & 131 & 4.9 & 134 & 5.0 \\
\hline Ultra-processed & 3943 & $30 \cdot 6$ & 2656 & $20 \cdot 6$ & 3505 & $27 \cdot 2$ & 1680 & $13 \cdot 0$ & 1707 & $13 \cdot 3$ & 1204 & $9 \cdot 4$ & 1085 & 8.4 \\
\hline Poti et al. ${ }^{(7)}$ & & & & & & & & & & & & & & \\
\hline Unprocessed/minimally processed & 339 & 13.7 & 683 & 27.5 & 318 & $12 \cdot 8$ & 99 & 4.0 & 535 & 21.5 & 170 & $6 \cdot 9$ & 194 & $7 \cdot 8$ \\
\hline Basic processed & 344 & $18 \cdot 4$ & 452 & $24 \cdot 1$ & 326 & $17 \cdot 4$ & 63 & 3.4 & 383 & $20 \cdot 4$ & 150 & $8 \cdot 0$ & 128 & $6 \cdot 8$ \\
\hline Moderately processed & 765 & 20.5 & 795 & 21.3 & 616 & $16 \cdot 5$ & 357 & $9 \cdot 6$ & 524 & 14.0 & 301 & 8.1 & 220 & 5.9 \\
\hline Highly processed & 3700 & $30 \cdot 0$ & 2404 & $19 \cdot 3$ & 3278 & $26 \cdot 4$ & 1591 & $12 \cdot 8$ & 1546 & $12 \cdot 4$ & 1068 & $8 \cdot 6$ & 987 & 7.9 \\
\hline
\end{tabular}

IFIC, International Food Information Council.

indicated that most referred to the fat content of the product (including references to total fat, saturated fat and trans fat); least common were references to sodium (Fig. 3). Irrespective of the classification scheme used, less than $3 \%$ of products deemed most processed bore regulated claims indicative of product reformulation to lower negative nutrients (data not shown).

While most positive nutrition references were found on products characteristic of the highest degree of processing (Table 2), when compared with lesser-processed products, they were less likely to bear this type of reference when the Poti et al. classification system was applied, but results were inconsistent across the other two classification systems (Table 3). The presence of an unregulated positive nutrition reference was more likely to appear on 'ready-to-eat' processed foods than on lesser-processed products when the IFIC classification system was applied, but results were inconsistent with the other two coding schemes (Table 3). No statistically significant differences were observed in the odds of ultra-processed products bearing unregulated 
positive references when they were compared with processed culinary ingredients, as coded by the NOVA system (Table 3). Similarly, the odds of unregulated positive references on highly processed products were not statistically significant when compared with basic and moderately processed foods, as coded by the Poti et al. system (Table 3).

When processing was coded using the NOVA system, ultra-processed foods were significantly more likely than lesser-processed foods to bear a symbol or summary system, but no clear pattern was observed when assessing the presence of a symbol or summary system across levels of processing using the other two classification systems (Table 3).

\section{Discussion}

Our study represents the first systematic examination of the relationship between FOP references and the level of food processing. We found that, compared with less processed foods, those classified as most processed were more likely to bear FOP references and more likely to bear multiple references, regardless of the classification system used to define levels of food processing. In addition, products with the highest level of processing were more likely to bear FOP references to negative nutrients, including both regulated and unregulated references.

The prominence of 'negative' nutrition messaging on foods with the highest levels of processing is consistent with the reportedly high density of nutrients of public health concern among these food products ${ }^{(2,3,7-10)}$. The ubiquity of negative nutrition references on products in the highest category of processing must in part reflect the competitive nature of product marketing in this sector, but it may also reflect manufacturers' attempts to respond to public health messaging and allay consumers' concerns regarding excessive exposure to potentially harmful ingredients such as trans fat, added sugars and sodium. The use of negative references may also signal reformulation efforts to reduce the concentrations of these particular ingredients in products. However, to the extent that we could identity product reformulation through manufacturers' use of regulated claims indicating lower amounts of energy, fat, sugar or sodium, we found little evidence of this practice, with fewer than $3 \%$ of the most processed products bearing such claims.

Nearly $24 \%$ of all products in our data set bore nutrition references which were unregulated, and unregulated references to negative nutrients were particularly prevalent on foods deemed most processed. While most work examining FOP references on pre-packaged foods has not differentiated regulated and unregulated nutrition information, research conducted on some specific product groups suggests that the presence of an unregulated nutrition reference may indicate a product that is nutritionally inferior to those bearing a regulated claim ${ }^{(18,19)}$. Insofar as public health authorities see the development of 
Table 4 Results of negative binomial regression models on total number of front-of-package references, by level of processing, across three classification systems, on packaged foods ( $n$ 20 520) from three large Toronto supermarkets, Canada, July 2010-August 2011

\begin{tabular}{|c|c|c|c|c|c|c|c|}
\hline \multirow[b]{2}{*}{ Classification system/processing level } & \multirow[b]{2}{*}{$n$} & \multirow[b]{2}{*}{ Mean } & \multirow[b]{2}{*}{ SD } & \multicolumn{4}{|c|}{ Model } \\
\hline & & & & $\beta$ & SE & $\exp (\beta)$ & $P$ value \\
\hline \multicolumn{8}{|l|}{$\mathrm{IFIC}^{(33)}$} \\
\hline Minimally processed & 2549 & $1 \cdot 28$ & 2.49 & -0.49 & 0.036 & 0.61 & $<0.001$ \\
\hline Processed for preservation & 2860 & 1.66 & $2 \cdot 13$ & -0.23 & 0.033 & 0.79 & $<0.001$ \\
\hline Mixtures of combined ingredients & 5835 & $1 \cdot 33$ & $2 \cdot 60$ & -0.45 & 0.027 & 0.64 & $<0.001$ \\
\hline Pre-prepared meals & 1662 & 1.43 & $2 \cdot 30$ & -0.38 & 0.420 & 0.68 & $<0.001$ \\
\hline 'Ready-to-eat' processed* & 7618 & $2 \cdot 10$ & 1.98 & - & - & - & - \\
\hline \multicolumn{8}{|l|}{$\mathrm{NOVA}^{(32)}$} \\
\hline Minimally processed & 6821 & 1.41 & $2 \cdot 15$ & -0.36 & 0.024 & 0.69 & $<0.001$ \\
\hline Processed culinary ingredients & 755 & 1.58 & $2 \cdot 60$ & -0.24 & 0.056 & 0.79 & $<0.001$ \\
\hline Processed food products & 2684 & 1.02 & 1.76 & -0.67 & 0.035 & 0.52 & $<0.001$ \\
\hline Ultra-processed* & 10260 & $2 \cdot 01$ & 2.59 & - & - & - & - \\
\hline \multicolumn{8}{|l|}{ Poti et al. ${ }^{(7)}$} \\
\hline Unprocessed/minimally processed & 6852 & $1 \cdot 73$ & $2 \cdot 36$ & -0.11 & 0.034 & 0.90 & $<0.001$ \\
\hline Basic processed & 991 & $1 \cdot 28$ & $2 \cdot 14$ & -0.41 & 0.027 & 0.66 & $<0.001$ \\
\hline Moderately processed & 3212 & 1.49 & 2.58 & -0.25 & 0.032 & 0.78 & $<0.001$ \\
\hline Highly processed* & 9465 & 1.92 & 2.53 & - & - & - & - \\
\hline
\end{tabular}

IFIC, International Food Information Council.

*Indicates highest processing level for each classification system and reference category.

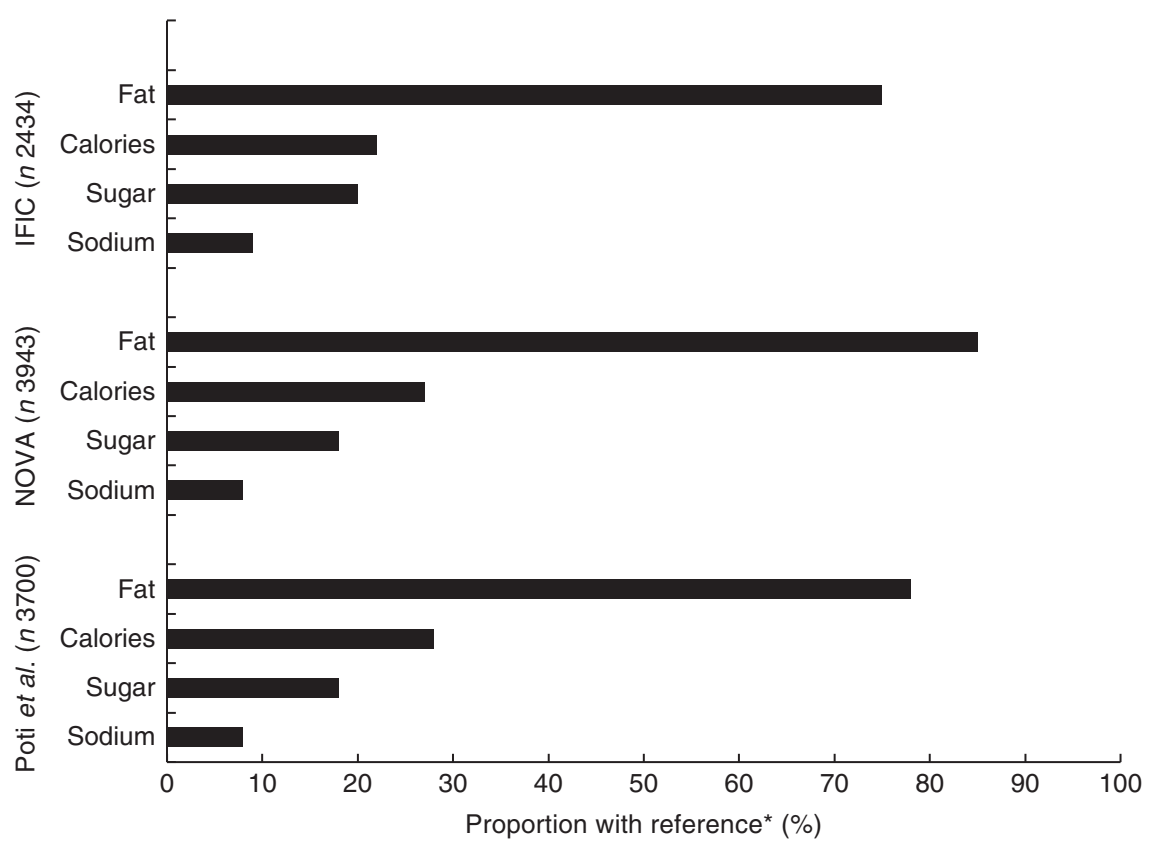

Fig. 3 Proportion of fat, energy (calorie), sugar and sodium references among 'negative' referenced products in the highest level of processing, by classification system, on packaged foods ( $n$ 20520) from three large Toronto supermarkets, Canada, July 2010August 2011. *Negative' references were coded to include a variety of text under a single term; e.g. references that referred to the fat content of a product included trans fat, saturated fat and total fat content (IFIC, International Food Information Council classification system ${ }^{(33)}$; NOVA, system developed by Monteiro and colleagues ${ }^{(32)}$; Poti et al., classification system developed by Poti and colleagues ${ }^{(7)}$ )

regulated FOP references as both a tool to provide nutritional guidance to consumers and an incentive for manufacturers to reformulate products to achieve better nutrient profiles ${ }^{(16)}$, manufacturers' use of unregulated text merits further study. It is important to recognize that consumers are unlikely to be capable of differentiating between FOP references that are regulated and ones that are not. Future research is needed to better understand manufacturers' motivations for using unregulated references and the implication of these labels for product sales.

We employed three distinct classification systems in our study as a means to better understand the relationship between product processing and the presence of FOP nutrition references. All three systems yielded similar results with respect to the greater presence of FOP nutrition labels in general and negative nutrition references, in 
particular, on products considered to be in the highest category of processing. However, several discrepancies surfaced when we considered manufacturers' use of positive nutrition references because different research groups classify some processed foods with particular nutritional properties differently. Closer examination of the discrepancies highlighted the effects of the differential classification of some specific food products across these three systems on our findings. For example, the highly significant lower odds of regulated positive nutrition references on highly processed foods than on less processed food categories, as defined by Poti et al., reflect the exclusion of some products made with whole grains (e.g. wholegrain breads and cereals) and commonly labelled with regulated fibre claims from the most highly processed category in this system ${ }^{(7,32,33)}$. This exclusion lessened the potential for positive nutrition references in this category relative to the most processed food category in the other two classification systems. Inconsistent results were also observed across systems when examining the presence of unregulated positive references. Foods classified as most processed under the IFIC system (i.e. 'ready-to-eat processed' foods) were more likely than others to bear positive unregulated references, but the pattern was less clear when examining this relationship using the other two systems. The explanation for this discrepancy appears to lie in the different classifications of convenience foods across the three systems. Convenience products, with a lower density of unregulated positive references, were classified in the highest degree of processing under NOVA and Poti et al., but not in the highest category of $\mathrm{IFIC}^{(41)}$. Although subtle, the differences in food classification across systems may have important implications for research results, as demonstrated in our current analyses. Researchers should be cognizant of these differences when choosing a classification system to define food processing; the three systems applied here are clearly not interchangeable.

Although the work presented here represents a robust assessment of FOP nutrition references on processed foods, some limitations should be considered in the interpretation of our results. First, the data were collected over a one-year period in 2010-2011 and therefore may not be reflective of the current food marketplace. References to sodium, for instance, might be more prevalent on foods now than when our data were collected, given the heightened public awareness of sodium levels in the Canadian food supply following the release of Canada's Sodium Reduction Strategy ${ }^{(43,44)}$. Similarly, the more recent liberalization of fortification polices in Canada, which affords manufacturers expanded opportunities for micronutrient additions to processed food products ${ }^{(45)}$, may now also translate into a greater frequency of positive nutrition references than observed on heavily processed products in the present study. More research is required to determine how dynamic manufacturers' use of discretionary FOP nutrition references is in the face of shifting public health priorities and new opportunities for product innovation.

Our study was also limited by our lack of nutritional content information and data on product sales. Although there is considerable evidence to suggest that FOP nutrition references do not necessarily signify nutritionally superior products ${ }^{(22-24)}$, there is limited research on the effects of these references on food selection and purchasing behaviours. Future work would benefit from an examination of how the use of FOP references by manufacturers impacts consumer behaviour and the nutritional quality of their diets.

Our examination of FOP nutrition references on packaged foods sold in Canadian supermarkets reflects manufacturers' practices at one point in time, in a regulatory environment where the use of some specific nutrient content claims is regulated but the display of both regulated and unregulated nutrition references is at the discretion of the manufacturer. Our finding that FOP nutrition references and references to 'negative' ingredients, in particular, were significantly more likely to appear on heavily processed foods raises questions about the adequacy of this form of nutrition guidance to direct consumers towards healthier food choices. The evolving discourse on FOP labelling in North America has so far focused on the nutrient requirements for a standardized, but still discretionary, FOP label that provides a more global assessment of the nutritional value of a product ${ }^{(36)}$. Our findings add to this discussion by highlighting the markedly different FOP labelling practices on foods with different levels of processing. Implementation of a mandatory, standardized system is necessary to ensure that the nutritional value of all foods available for sale is communicated to consumers ${ }^{(46)}$. Failing this, regulators should perhaps consider calls for the abolition of the practice of FOP nutrition referencing, as put forward by others ${ }^{(26,47)}$.

\section{Acknowledgements}

Acknowledgements: The authors gratefully acknowledge Dr Jocelyn Sacco for her initial support in the development of the database. Financial support: This study was funded by an operating grant from the Canadian Institutes of Health Research (grant number MOP - 102655). The Canadian Institutes of Health Research had no role in the design, analysis or writing of this article. Conflict of interest: The authors have no competing interests to declare. Authorship: V.T., R.M. and N.D. designed the overall study and secured the funding. A.C. and V.T. designed and conducted the analyses and drafted the manuscript. All authors participated in the interpretation of the findings, critically reviewed the manuscript and approved the final version. Ethics of human subject participation: Not applicable. 


\section{Supplementary material}

To view supplementary material for this article, please visit https://doi.org/10.1017/S1368980017001057

\section{References}

1. Monteiro CA, Moubarac JC, Cannon G et al. (2013) Ultraprocessed products are becoming dominant in the global food system. Obes Rev 14, Suppl. 2, 21-28.

2. Moubarac JC, Batal M, Martins APB et al. (2014) Processed and ultra-processed food products: consumption trends in Canada from 1938 to 2011. Can J Diet Pract Res 75, 15-21.

3. Moubarac JC, Batal M, Louzada ML et al. (2017) Consumption of ultra-processed foods predicts diet quality in Canada. Appetite 108, 512-520.

4. Monteiro CA, Levy RB, Claro RM et al. (2011) Increasing consumption of ultra-processed foods and likely impact on human health: evidence from Brazil. Public Health Nutr 14, 5-13.

5. Stuckler D, McKee M, Ebrahim S et al. (2012) Manufacturing epidemics: the role of global producers in increased consumption of unhealthy commodities including processed foods, alcohol, and tobacco. PLoS Med 9, e1001235.

6. Moodie R, Stuckler D, Monteiro C et al. (2013) Profits and pandemics: prevention of harmful effects of tobacco, alcohol, and ultra-processed food and drink industries. Lancet 381, 670-679.

7. Poti JM, Mendez MA, Ng SW et al. (2015) Is the degree of food processing and convenience linked with the nutritional quality of foods purchased by US households? Am J Clin Nutr 101, 1251-1262.

8. Moubarac JC, Martins APB, Claro RM et al. (2013) Consumption of ultra-processed foods and likely impact on human health. Evidence from Canada. Public Health Nutr 16, 2240-2248.

9. Steele EM, Baraldi LG, da Costa Louzada ML et al. (2016) Ultra-processed foods and added sugars in the US diet: evidence from a nationally representative crosssectional study. BMJ Open 6, e009892.

10. Eicher-Miller HA, Fulgoni VL \& Keast DR (2012) Contributions of processed foods to dietary intake in the US from 2003-2008: a report of the Food and Nutrition Science Solutions Joint Task Force of the Academy of Nutrition and Dietetics, American Society for Nutrition, Institute of Food Technologists, and International Food Information Council. J Nutr 142, issue 11, 2065S-2072S.

11. Canella DS, Levy RB, Martins APB et al. (2014) Ultraprocessed food products and obesity in Brazilian households (2008-2009). PLoS One 9, e92752.

12. Tavares LF, Fonseca SC, Rosa MLG et al. (2012) Relationship between ultra-processed foods and metabolic syndrome in adolescents from a Brazilian Family Doctor Program. Public Health Nutr 15, 82-87.

13. Moubarac JC (2012) The big issue is ultra-processing. Sexing up ultra-processed products (Commentary). World Nutr $\mathbf{3}$, 62-80.

14. Mallarino C, Gómez LF, González-Zapata L et al. (2013) Advertising of ultra-processed foods and beverages: children as a vulnerable population. Rev Saude Publica $\mathbf{4 7}$, 1006-1010.

15. Health Canada (2015) Food labelling. http://www.hc-sc. gc.ca/fn-an/label-etiquet/index-eng.php (accessed September 2016).

16. Health Canada (2015) Consulting Canadians to modernize and improve food labels: what we heard. http://www.hcsc.gc.ca/fn-an/label-etiquet/modernize-report-moderniserrapport-eng.php (accessed October 2016).
17. Schermel A, Emrich TE, Arcand J et al. (2013) Nutrition marketing on processed food packages in Canada: 2010 Food Label Information Program. Appl Physiol Nutr Metab 38, 666-672.

18. Sacco JE, Sumanac D \& Tarasuk V (2013) Front-ofpackage references to fibre on foods in Canadian supermarkets highlight the need for increased nutrition knowledge among consumers. J Nutr Educ Behav $\mathbf{4 5}$, 518-524.

19. Metcalfe A \& Elliott C (2015) Differences in the nutritional content of baby and toddler foods with front-of-package nutrition claims issued by manufacturers $v$. governments/ health organizations. Public Health Nutr 18, 75-80.

20. Colby SE, Johnson L, Scheett A et al. (2010) Nutrition marketing on food labels. J Nutr Educ Behav 42, 92-98.

21. Dachner N, Mendelson R, Sacco J et al. (2015) An examination of the nutrient content and on-package marketing of novel beverages. Appl Physiol Nutr Metab 40, 191-198.

22. Emrich TE, Qi Y, Cohen JE et al. (2015) Front-of-pack symbols are not a reliable indicator of products with healthier nutrient profiles. Appetite 84, 148-153.

23. Ricciuto L, Ip H \& Tarasuk V (2005) The relationship between price, amounts of saturated and trans fats, and nutrient content claims on margarines and oils. Can J Diet Pract Res 66, 252-255.

24. Van Camp D, de Souza Monteiro DM \& Hooker NH (2012) Stop or go? How is the UK food industry responding to front-of-pack nutrition labels? Eur Rev Agric Econ 39, 821-842.

25. Volkova E \& Mhurchu CN (2015) The influence of nutrition labeling and point-of-purchase information on food behaviours. Curr Obes Rep 4, 19-29.

26. Nestle M \& Ludwig DS (2008) Can the food industry play a constructive role in the obesity epidemic? JAMA $\mathbf{3 0 0}$, 1808-1811.

27. World Health Organization (2003) Diet, Nutrition and the Prevention of Chronic Diseases. Report of a Joint WHO/FAO Expert Consultation. WHO Technical Report Series no. 916. Geneva: WHO.

28. Fischer PW, Vigneault M, Huang R et al. (2009) Sodium food sources in the Canadian diet. Appl Physiol Nutr Metab 34, 884-892.

29. Garriguet D (2008) Beverage consumption of Canadian adults. Health Rep 19, 23-29.

30. Brisbois TD, Marsden SL, Anderson GH et al. (2014) Estimated intakes and sources of total and added sugars in the Canadian diet. Nutrients 6, 1899-1912.

31. Health Canada (2016) Healthy Eating Strategy. https:// www.canada.ca/content/dam/canada/health-canada/migra tion/publications/eating-nutrition/healthy-eating-strategycanada-strategie-saine-alimentation/alt/pub-eng.pdf (accessed December 2016).

32. Monteiro CA, Cannon G, Levy RB et al. (2012) The food system. Processing. The big issue for disease, good health, well-being. World Nutr 3, 527-569.

33. International Food Information Council Foundation (2010) Understanding our food communications tool kit. http:// www.foodinsight.org/For-Professionals/Understanding-OurFood/tabid/1398/Default.aspx (accessed August 2015).

34. Sumanac D, Mendelson R \& Tarasuk V (2013) Marketing whole grain breads in Canada via food labels. Appetite $\mathbf{6 2}$, $1-6$.

35. Canadian Grocer (2009) Canadian Grocery Industry 2008: Executive Report. Toronto, ON: Rogers Media Publishing.

36. Institute of Medicine (2011) Front-of-Package Nutrition Rating Systems and Symbols: Promoting Healthier Choices [EA Wartella, AH Lichtenstein and CS Boon, editors]. Washington, DC: National Academies Press. 
37. Government of Canada (2003) Regulations amending the Food and Drug Regulations (nutrition labelling, nutrient content claims and health claims). The Canada Gazette, Part II 137, 154-403.

38. Canadian Food Inspection Agency (2014) Guide to food labelling and advertising. http://www.inspection.gc.ca/ english/fssa/labeti/guide/toce.shtml (accessed September 2014).

39. Poti J, Mendez M, Ng SW et al. (2015) Ultra-processed and ready-to-eat food and beverage purchases differ by race, education, and income in a longitudinal US study. FASEB J 29, 1 Suppl., 251-252.

40. Eicher-Miller HA, Fulgoni VL \& Keast DR (2015) Energy and nutrient intakes from processed foods differ by sex, income status, and race/ethnicity of US adults. J Acad Nutr Diet 115, 907-918.

41. Moubarac JC, Parra DC, Cannon G et al. (2014) Food classification systems based on food processing: significance and implications for policies and actions: a systematic literature review and assessment. Curr Obes Rep 3, 256-272.
42. Gardner W, Mulvey EP \& Shaw EC (1995) Regression analyses of counts and rates: Poisson, overdispersed Poisson, and negative binomial models. Psychol Bull 118, 392-404.

43. Sodium Working Group (2010) Sodium Reduction Strategy for Canada: Recommendations of the Sodium Working Group. Ottawa, ON: Health Canada.

44. Canadian Council of Food and Nutrition (2013) Tracking Nutrition Trends: A 20-Year History. Mississauga, ON: CCFN.

45. Health Canada (2014) Lists of foods that have received Temporary Marketing Authorization Letters. http://www. hc-sc.gc.ca/fn-an/legislation/acts-lois/list-tmal-rpsn-eng.php (accessed July 2014).

46. Center for Science in the Public Interest (2015) Nutrition labeling for public health impact. http://cspinet.org/canada/ pdf/with-surveydata.final.april23-2015-cspi-billjeffery.nutri tionlabelling-for-public-health-impact.pdf (accessed September 2015)

47. Scrinis G (2016) Reformulation, fortification and functionalization: Big Food corporations' nutritional engineering and marketing strategies. J Peasant Stud 43, 17-37. 